\title{
Mindfulness for Sustainable Internet Use in Chinese Junior Secondary School Students: A Dual-Path Mediation Model
}

\author{
Jianfen $\mathrm{Wu}^{1, *(\mathbb{D})}$ and Hui $\mathrm{Li}^{2}$ (D) \\ 1 School of Education, Hangzhou Normal University, Hangzhou 311121, China \\ 2 School of Education, Macquarie University, Macquarie Park, NSW 2109, Australia; philip.li@mq.edu.au \\ * Correspondence: ppwu70@hznu.edu.cn
}

Citation: $\mathrm{Wu}, \mathrm{J} . ; \mathrm{Li}, \mathrm{H}$. Mindfulness for Sustainable Internet Use in Chinese Junior Secondary School Students: A Dual-Path Mediation Model. Sustainability 2021, 13, 4626. https://doi.org/10.3390/su13094626

Academic Editor: Sandro Serpa

Received: 14 March 2021

Accepted: 19 April 2021

Published: 21 April 2021

Publisher's Note: MDPI stays neutral with regard to jurisdictional claims in published maps and institutional affiliations.

Copyright: (C) 2021 by the authors. Licensee MDPI, Basel, Switzerland. This article is an open access article distributed under the terms and conditions of the Creative Commons Attribution (CC BY) license (https:// creativecommons.org/licenses/by/ $4.0 /)$.

\begin{abstract}
Mindfulness training can reduce Internet addiction and promote sustainable development, but the possible mediators of this impact have not been thoroughly explored. This study explored the mediating roles of self-control and maladaptive cognitions in the association between mindfulness and Internet addiction to fill this gap. Altogether, 771 Chinese adolescents $(M=13.87$ years, $S D=0.78$ years) were surveyed about their mindfulness, self-control, maladaptive cognitions, and Internet addiction. The confirmed model presented a good model fit and revealed that (i) mindfulness, self-control, maladaptive cognitions, and Internet addiction were significantly correlated; (ii) mindfulness had indirect negative effects on Internet addiction, mediated by self-control; (iii) mindfulness had an indirect negative impact on Internet addiction, mediated by the path of self-control to maladaptive cognitions; and (iv) this dual-path mediation model might apply to male and female adolescents. The results of the present study suggest that both self-control and maladaptive cognitions are key factors in the association between mindfulness and Internet addiction.
\end{abstract}

Keywords: internet addiction; mindfulness; self-control; maladaptive cognitions; dual-path mediation model

\section{Introduction}

Internet addiction is a growing problem that has many harmful effects on adolescents' health and wellbeing [1-3]. The existing studies have confirmed that it has been associated with negative emotions [4,5]), physical health challenges [6,7], and psychological dysfunction [8,9]. It is thus critical to identify and implement some effective measures to prevent adolescents from becoming addicted to the Internet. Recently, some studies found that mindfulness might have indirect effects on Internet addiction $[10,11]$, but few studies have explored this impact's possible mediators. To fill this gap, this study proposed and examined a dual-path mediation model with a large-scale survey of Chinese adolescents, focusing on the mediating roles of self-control and maladaptive cognitions in the model.

\section{Literature Review \\ 2.1. Mindfulness and Internet Addiction}

Most studies have aimed to identify harmful predictors of Internet addiction, such as low self-esteem [12,13], low self-control [14,15], and maladaptive cognitions [16,17]. However, these studies have overlooked factors protecting against Internet addiction. For example, mindfulness, which was described as "the awareness that emerges through paying attention on purpose, in the present moment, and nonjudgmentally to the unfolding of experience moment by moment" $[18,19])$. Notably, the reperceiving model of mindfulness implies that mindfulness can help people allow their thoughts to come and go without becoming overwhelmed by them, reacting to them, or trying to control, change, or suppress them [19]. Mindfulness has been associated with better physical and mental health, such as self-esteem, positive affect, sleep quality, and subjective wellbeing [20,21]. Mindfulness also contributes to alleviating addictive behaviors, such as mobile phone addiction and Internet 
addiction. For example, Liu et al. determined that the association between perceived stress and mobile phone addiction was moderated by trait mindfulness-more specifically, the association was stronger for individuals with low mindfulness than those with high mindfulness [22]. Additionally, many studies have demonstrated that mindfulness training courses can effectively decrease mobile phone addiction and Internet addiction $[10,11])$. Although studies have identified the protective role of mindfulness against Internet addiction, few have tested the mechanism of how mindfulness prevents Internet addiction. Thus, this study addressed this gap by exploring the direct and indirect effects of mindfulness on Internet addition.

\subsection{Mediating Roles of Self-Control and Maladaptive Cognitions}

Cognitive-behavioral models offer theoretical explanations of the pathogenesis and origins of Internet addiction. In the models, psychopathology (such as depression, substance dependence, and social anxiety) is a necessary distal cause of Internet addiction symptoms [23]. However, the underlying psychopathology is a necessary element in its etiology and does not result in symptoms of Internet addiction. Notably, maladaptive cognitions about the Internet are among the causes of Internet addiction, for example, "online friends are more trustworthy than my real-world friends" [23]. Furthermore, studies have indicated that distal psychopathology renders an individual vulnerable to Internet addiction through maladaptive cognitions $[16,17]$. In the reperceiving model of mindfulness, mindfulness can help people reperceive moment-by-moment experiences with greater objectivity, overcome automatic behavioral and emotional patterns, and facilitate adaptive cognitions to negative stimulation [22,24]. From this perspective, mindfulness tends to be a distal factor protecting against Internet addiction symptoms that can decrease vulnerability to Internet addiction associated with maladaptive cognitions.

Additionally, existing studies have found Internet addiction mainly results from a failure of self-regulation due to a lack of self-control (which can be defined as the capacity to stick to a long-term goal by resisting inner desires and external temptations), which makes individuals unable to resist an increasing craving and prevents the transition from normal use to addiction [14,15]. In self-regulation theory, a lack of self-control can lead to failure in self-regulation; individuals with little self-regulation have difficulty resisting an increasing craving to use the Internet, which in turn leads to addictive behaviors $[10,11]$. Fortunately, mindfulness, as the deliberate self-control of attention, consists of being aware of the present experience. Therefore, self-control is another factor protecting against Internet addiction. Numerous researchers have reported that mindfulness is positively related to the level of self-control [25-27]. Thus, mindfulness may prevent Internet addiction symptoms through increasing self-control. Additionally, Song and Park reported that individuals with low self-control tend to experience Internet addiction by developing maladaptive cognitions about the Internet [28]. This self-control tends to be a distal protective predictor of Internet addiction. In the cognitive-behavioral model, mindfulness may also prevent Internet addiction through self-control and maladaptive cognitions. Thus, this study explored the possible mediators of the path from mindfulness to Internet addiction.

\subsection{Gender Differences in Internet Addiction}

Gender difference in Internet addiction has long been debated in the literature. Some authors have suggested that female students have a higher level of Internet addiction because they are more likely to use social networking services, such as Facebook, where they can upload pictures for purposes of self-advertisement and self-expression [29-31]. However, others have suggested male students have a higher level of Internet addiction, as they are more likely to play computer games for entertainment [2,32]. When playing computer games, male students spend prolonged periods on the Internet, resulting in their having a higher level of Internet addiction. Thus, additional research was required to test for gender differences in Internet addiction. Additionally, a gender difference in Internet addiction may be caused by different associations among mindfulness, self-control, 
maladaptive cognitions, and Internet addiction. Thus, the present study also examined whether the mediation models of mindfulness, self-control, maladaptive cognitions, and Internet addiction are different for male and female adolescents.

\subsection{This Study}

The existing studies have suggested that junior secondary students are a special group concerning Internet addiction [33]. This is because they are adolescents and in the beginning stage of adulthood, and their parents and teachers might give them more time and freedom (compared to their primary school time) [34]. Therefore, junior secondary school students tend to have higher levels of Internet addiction than primary school students. In addition, junior secondary school students have a less demanding workload compared to high school students, and thus, can have more time to play on the Internet [35]. Therefore, junior secondary school students have more time, freedom, less study pressure, and more opportunities to become Internet-addicted than primary and high school students. The junior secondary school period might be the critical period for implementing prevention programs and fighting against Internet addiction. We wanted to explore and understand the possible influential factors and their working mechanisms in junior secondary school students.

Accordingly, this study's aim was two-fold. The first was to explore the mediating roles of self-control and maladaptive cognitions in the association between mindfulness and Internet addiction. The second was to determine whether there are gendered models. Specifically, the following questions guided this study:

1. Does mindfulness have a direct negative effect on Internet addiction in Chinese adolescents? If not, does it impact Internet addiction indirectly?

2. Is the path from mindfulness to Internet addiction mediated by self-control?

3. Is the path from mindfulness to Internet addiction mediated maladaptive cognition?

Based on the literature review, we proposed a dual-path mediation model (see Figure 1) and hypothesized the following:

Hypothesis 1 (H1). Mindfulness can negatively predict Internet addiction directly. Hypothesis 2 (H2). Mindfulness can negatively predict Internet addiction indirectly through self-control.

Hypothesis 3 (H3). Mindfulness can negatively predict Internet addiction indirectly through maladaptive cognitions.

Hypothesis 4 (H4). Mindfulness can negatively predict Internet addiction indirectly through the path of self-control to maladaptive cognitions.

Hypothesis 5 (H5). The mediation model differs for each gender.

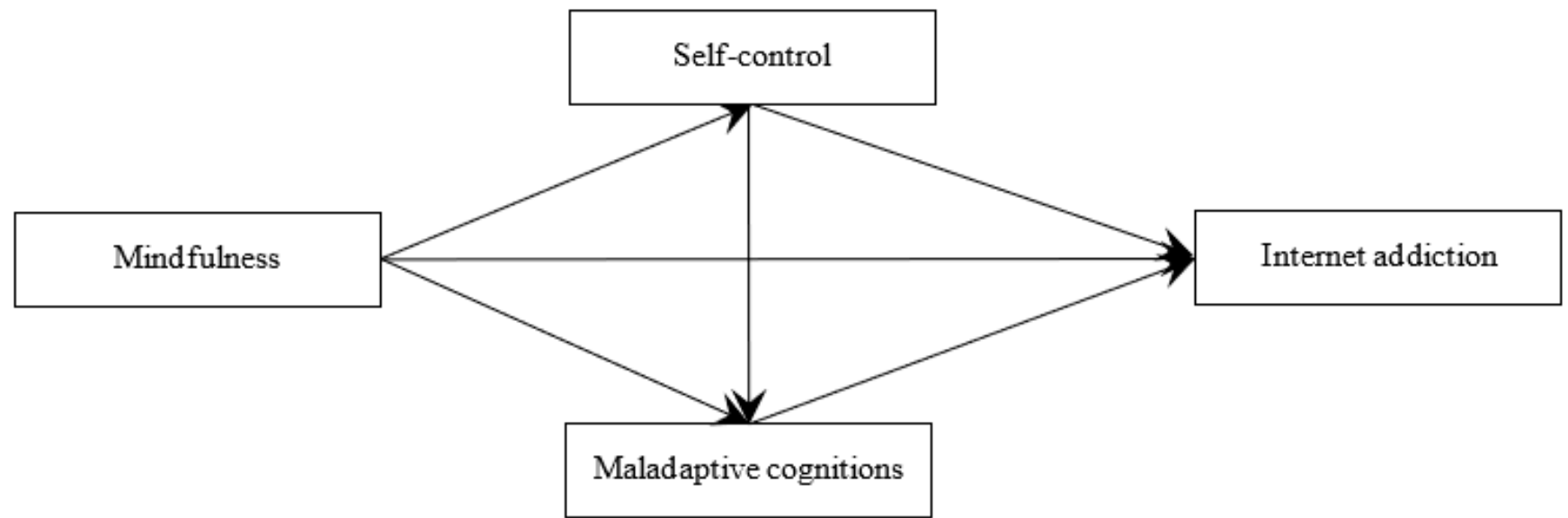

Figure 1. The proposed dual-path mediation model. 


\section{Materials and Methods}

\subsection{Participants}

A total of 771 students (368 boys and 403 girls; $M_{\text {age }}=13.87$ years, $S D=0.78$ years) were sampled from one junior secondary school in City $X$ of northeast China for this study. With the current sample size, the power was sufficient to detect any medium effect (power of 0.98 for at least a medium effect size). Their parents were invited to consider whether to let their children participate part in this study. Only students whose parents signed the consent form in accordance with the Declaration of Helsinki were recruited and surveyed. A team of research assistants (RA) came to the school to instruct and guide the participants to complete the classroom survey. Before the survey, the RAs briefed the students about the survey purpose and assured them of their responses' anonymity. The RAs had been well-trained to address all the questions the students might raise during the survey. In addition, the class teacher was present during the survey to maintain discipline. Finally, all the students who submitted the completed questionnaire received a pen as a survey reward.

\subsection{Measures}

Chinese Mindfulness Scale. Trait mindfulness was assessed using the Chinese Mindfulness Scale [36]. It has 38 items and adopts the 5-point Likert scale, ranging from 1 (completely disagree) to 5 (completely agree). Example questions include "I seem to be doing something automatically rather than being fully aware of it" and "Usually, when I have a sad thought or image, I can quickly regain calm". The total scores of the 38 items were calculated as the indicator of each student's mindfulness, with higher scores representing higher mindfulness. The Cronbach's $\alpha$ coefficient for the items was 0.82 .

Self-control Scale. The Chinese version of the Self-Control Scale $[37,38]$ was employed in this study. It consists of 19 items and adopts the 5-point Likert scale, ranging from 1 (strongly disagree) to 5 (strongly agree). Example questions include "Sometimes I get distracted by fun and can't finish the task on time" and "I will do something that can bring me happiness but is harmful to me". The total scores of the 19 items were calculated as the indicator of self-control, with higher scores representing higher self-control. The Cronbach's $\alpha$ coefficient for these items was 0.88 .

Maladaptive Cognitions Scale. Maladaptive cognitions were assessed using the Chinese version of the Maladaptive Cognitions Scale $[39,40]$. It has 14 items and employs the 5-point Likert Scale, ranging from 1 (strongly disagree) to 5 (strongly agree). Example questions include "I feel that online life is more exciting than real life" and "I get to know others better online than in real life". The total scores of the 14 items were calculated as the indicator of Maladaptive cognition. The Cronbach's $\alpha$ coefficient for these items was 0.95.

Internet Addiction Scale. Internet addiction was assessed using the Chinese version of the Internet Addiction Scale [41]. It has 11 items and adopts the 7-point Likert scale, ranging from 1 (strongly disagree) to 7 (strongly agree). Example questions include "Due to too much Internet, you neglect your homework or fail to get the ideal result on an exam" and "Although you know that surfing the Internet for a long time is harmful to you, you still can't control yourself". The total scores of 11 items were calculated as the indicator of Internet addiction, with higher scores representing higher Internet addiction. The Cronbach's $\alpha$ coefficient for these items was 0.93 .

\subsection{Statistical Analyses}

First, SPSS 21.0 was employed to conduct the descriptive statistics, correlation analysis, and gender difference tests.

Second, MPLUS 7.0 was used to conduct the structural equation modeling (SEM) to test the mediating roles of self-control and maladaptive cognitions in the association between mindfulness and Internet addiction. Multiple group comparisons were also made to test whether association patterns differed by gender. In the mediating model, the total scores of each studied variable were used as the observed variables. The SEM analyses 
adopted a robust maximum likelihood estimation [42]. $\chi^{2}$ was used as the primary criterion to evaluate model fit, as it is sensitive to large samples [43]). The root-mean-square error of approximation (RMSEA), the Tucker-Lewis index (TLI), and the comparative fit index (CFI) were also used to evaluate the model. RMSEA values of $\leq 0.08$ indicate good model fit; TLI and CFI of $>0.95$ indicate good model fit [44]. The chi-square test of difference $\left(\Delta \chi^{2}\right)$ was used to compare the fit of the nested models. A nonsignificant $\Delta \chi^{2}$ result indicates that two models provide an equal fit to the data, whereas a significant $\Delta \chi^{2}$ suggests that the less constrained model should be retained.

\section{Results}

\subsection{Descriptive Statistics, Correlation Analysis, and Gender Differences}

The means and standard deviations for mindfulness, self-control, maladaptive cognitions, and Internet addiction are presented in Table 1 . Table 1 also presents the associations between mindfulness, self-control, maladaptive cognitions, and Internet addiction. Mindfulness was positively associated with self-control, whereas it was negatively associated with maladaptive cognitions and Internet addiction. Self-control was negatively associated with maladaptive cognitions and Internet addiction. Maladaptive cognitions and Internet addiction were positively associated. These results indicate that being more mindful was associated with greater self-control, smaller maladaptive cognitions, and lesser Internet addiction. Having greater self-control was associated with smaller maladaptive cognitions and lesser Internet addiction. Having greater maladaptive cognitions was associated with greater Internet addiction.

Table 1. Descriptive statistics and correlation analysis of the studied variables.

\begin{tabular}{ccccc}
\hline Variables & $\mathbf{1}$ & $\mathbf{2}$ & $\mathbf{3}$ & $\mathbf{4}$ \\
\hline Mindfulness & 1 & & & \\
Self-control & $0.23^{* *}$ & 1 & & \\
Maladaptive cognitions & $-0.13^{* *}$ & $-0.50^{* *}$ & 1 & 1 \\
Internet addiction & $-0.15^{* *}$ & $-0.43^{* *}$ & $0.63^{* *}$ & 34.34 \\
M & 112.37 & 63.13 & 33.99 & 13.06 \\
SD & 15.00 & 12.17 & 12.30 &
\end{tabular}

Note: ** $p<0.01$.

Additionally, a series of independent-samples $t$-tests were conducted to examine gender differences in the studied variables; no gender differences were found for mindfulness, self-control, maladaptive cognitions, or Internet addiction (see Table 2).

Table 2. Gender difference test of the studied variables.

\begin{tabular}{ccccccc}
\hline Variables & Male $(\boldsymbol{M} \pm \boldsymbol{S D})$ & Female $(\boldsymbol{M} \pm \boldsymbol{S D})$ & $\boldsymbol{t}$ & $\boldsymbol{d} f$ & $\boldsymbol{p}$ & Cohen's d \\
\hline Mindfulness & $113.10 \pm 13.96$ & $111.69 \pm 15.89$ & 1.30 & 769 & 0.19 & 0.09 \\
Self-control & $62.85 \pm 12.88$ & $63.38 \pm 11.48$ & -0.60 & 769 & 0.55 & -0.04 \\
Maladaptive cognitions & $34.85 \pm 12.91$ & $33.21 \pm 11.68$ & 1.86 & 769 & 0.06 & 0.13 \\
Internet addiction & $35.28 \pm 13.93$ & $33.48 \pm 12.15$ & 1.91 & 769 & 0.06 & 0.14 \\
\hline
\end{tabular}

\subsection{Mediating Roles of Self-Control and Maladaptive Cognitions}

SEM was employed to test the mediating roles of self-control and maladaptive cognitions in the association between mindfulness and Internet addiction (see Figure 2). The results indicate that the model had good fit indices: $\chi^{2}(6)=670.19, p<0.001$, RMSEA $=0.00$, $\mathrm{TLI}=1.00, \mathrm{CFI}=1.00$. The results also suggest that mindfulness can positively predict self-control $(\beta=0.18, S E=0.04, p<0.01)$, self-control can negatively predict Internet addiction $(\beta=-0.16, S E=0.04, p<0.01)$ and maladaptive cognitions $(\beta=-0.50$, $S E=0.04, p<0.01$ ), and maladaptive cognitions can positively predict Internet addiction $(\beta=0.58, S E=0.04, p<0.01)$. However, mindfulness did not predict maladaptive cogni- 
tions $(\beta=-0.01, S E=0.02, p<0.01)$ or Internet addiction $(\beta=-0.04, S E=0.03, p<0.01)$ directly. A mediational effect is significant at the 0.05 level if the $95 \%$ confidence level does not include zero. The results indicate that mindfulness can influence Internet addiction through the mediational effect of self-control (95\% CI: -0.05 to -0.02$)$ and that mindfulness can also influence Internet addiction though the mediational effect of self-control on maladaptive cognitions ( $95 \% \mathrm{CI}:-0.08$ to -0.04$)$.

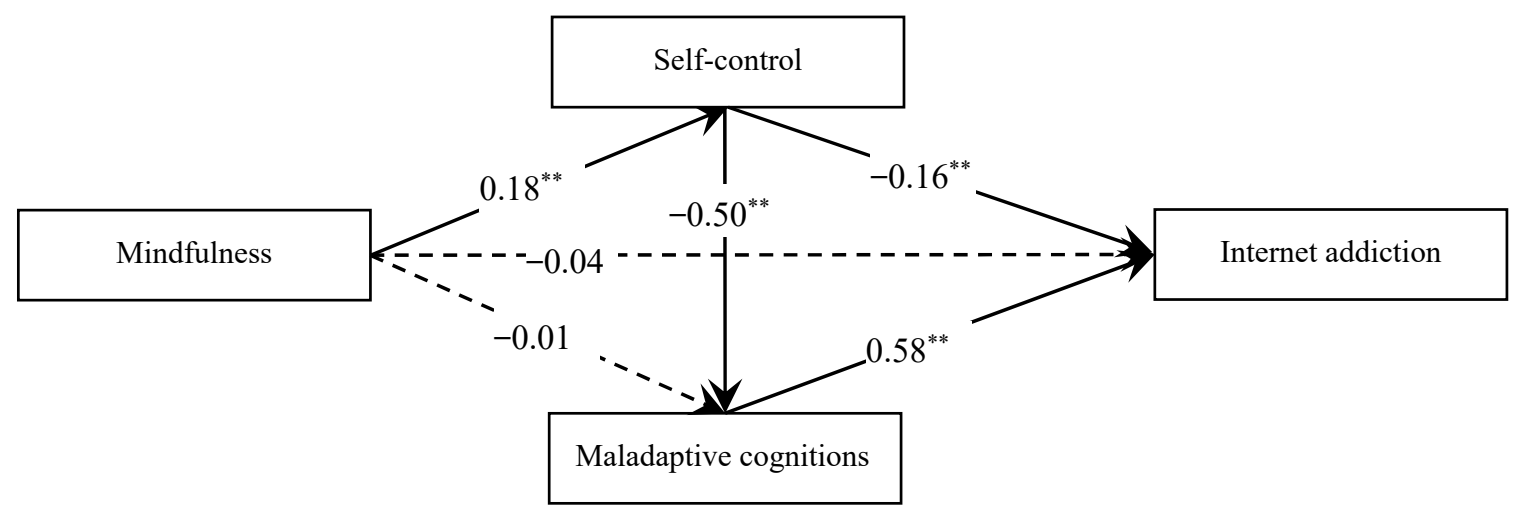

Figure 2. The confirmed dual-path mediation model. Note: ${ }^{* *} p<0.01$.

\subsection{Moderating Role of Gender}

To test for gender difference in the associations among mindfulness, self-control, maladaptive cognitions, and Internet addiction, multiple group comparisons were conducted. More specifically, gender was coded as a categorical variable, and the associations among the studied variables were individually tested using the aforementioned mediational model (which was defined as a fully unconstrained model). Each of the paths in the fully unconstrained model was constrained to be equal across male and female students in turn, and the models were then compared with the fully unconstrained model; significant $\Delta \chi^{2} / \Delta d f$ suggested a significant gender difference. The results of multiple group comparisons revealed no gender differences in the associations among mindfulness, self-control, maladaptive cognitions, and Internet addiction: mindfulness to self-control $\left(\Delta \chi^{2}=3.45, \Delta d f=1, p=0.06\right) ;$ mindfulness to Internet addiction $\left(\Delta \chi^{2}=0.07, \Delta d f=1\right.$, $p=0.79)$; mindfulness to maladaptive cognitions $\left(\Delta \chi^{2}=0.28, \Delta d f=1, p=0.60\right)$; self-control to maladaptive cognitions $\left(\Delta \chi^{2}=0.05, \Delta d f=1, p=0.82\right)$; self-control to Internet addiction $\left(\Delta \chi^{2}=0.38, \Delta d f=1, p=0.54\right)$; maladaptive cognitions to Internet addiction $\left(\Delta \chi^{2}=1.36\right.$, $\Delta d f=1, p=0.24)$.

\section{Discussion}

This study proposed and confirmed a dual-path mediation model as the first exploration of the mediating effects of self-control and maladaptive cognitions, which was consistent with previous studies to some extent [22,28,45-51]. This section will discuss this model and its implications for educational practices, using the self-regulation theory and the cognitive-behavioral model.

\subsection{Path 1: The Mediating Role of Self-Control}

Although many researchers have reported that mindfulness can be deployed to prevent Internet addiction, few have explored the mediating mechanism of the association between mindfulness and Internet addiction [10,11]. The present study results indicate that mindfulness affects Internet addiction through self-control, which is consistent with the self-regulation theory. Mindfulness can increase self-control by making the mind view the object of the Internet as it is - an object-instead of an object with exaggerated benefits [47]. Additionally, mindfulness can make an experience feel fresh and immersive rather than a habitual or automatic response [52], which suggests mindfulness can increase self-control. 
If an individual's self-control is increased, their level of Internet addiction may be decreased through self-regulation.

Although several studies have tested associations between mindfulness, self-control, and Internet addiction, the present study makes a special contribution in this area. For example, Song and Park reported mindfulness and self-control could partially mediate the relationship between stress and Internet addiction [28]; mindfulness was used as a mediating rather than an independent variable [53]. However, mindfulness was defined as a personality trait that is more appropriate for independent variables; the present study addressed this defect. Additionally, the sample in Song and Park's study consisted of adults; hence, studies with adolescents were required to supplement their results. The results of the present study are consistent with theirs and expand the interpretative scope of the results. Liu et al. also tested associations among mindfulness, self-control, and phone addiction [22]. They determined that mindfulness, self-control, and phone addiction were significantly associated, consistent with the findings of the present study. In their study, phone addiction, rather than Internet addiction, was used; however, the consistent results expand their findings' interpretative scope.

\subsection{Path 2: The Mediating Roles of Self-Control and Maladaptive Cognitions}

The present study results indicate that mindfulness can reduce Internet addiction through the path of self-control to maladaptive cognitions, which is a key finding. Although the cognitive-behavioral model posits many necessary distal causes and sufficient proximal causes for Internet addiction, the positions of mindfulness and self-control in the model were unclear [23]. The present study results suggest that mindfulness and self-control tend to be necessary distal causes and can limit Internet addiction arising with maladaptive cognitions. Thus, the results expand the cognitive-behavioral model. According to the model, individuals tend to exaggerate the Internet's benefits (maladaptive cognitions), which is a key factor in Internet addiction. Fortunately, mindfulness entails remaining neutral rather than exaggerating inner experiences through increased self-control, reducing Internet addiction [28]. Although previous studies have recognized the mediating role of self-control in the association between mindfulness and Internet addiction [22], the mediators in the association between self-control and Internet addiction required elaboration. The present study results suggest self-control can influence Internet addiction through maladaptive cognitions, which better describes the mediating mechanism in associations between mindfulness and Internet addiction.

\subsection{No Gender Difference and the Implications}

No gender difference was observed regarding Internet addiction, which is consistent with previous reports $[54,55]$. However, many studies have suggested that male students have a higher level of Internet addiction than female students [2,32]. These inconsistent results may be caused by the samples used. For example, Tian et al.'s study participants were university students, and university students have more freedom and leisure time, which may lead to their spending more time on the Internet. This is less the case for junior secondary school students. Furthermore, a low level of Internet addiction for male and female students may disguise a gender difference. Additionally, in the present study, the association patterns between mindfulness and Internet addiction were similar for male and female students, suggesting that they share the same mediating mechanism. The results suggest that the same intervention program for the association between mindfulness and Internet addiction and its mediating mechanism could be used for male and female students.

\subsection{Practical Implications}

Nevertheless, this study has contributed to theoretical development and practical improvement. Theoretically, this study has proposed and confirmed the dual-path mediation model for the first time. This new model implies multiple mediating paths from 
mindfulness to Internet addiction, which deserve further empirical explorations of any other possible mediators or moderators. For instance, maladaptive cognitions were found to play a mediating role in the association between shyness and Internet addiction over time [2]. In the future, studies with a longitudinal design could test whether self-control, maladaptive cognitions, and other variables could play dual or serial mediating roles in the association between mindfulness and Internet addiction over time. Practically, these findings have provided implications for program development to prevent Internet addiction. For instance, any training programs to enhance adolescents' mindfulness, self-control, and maladaptive cognitions in junior secondary schools would help fight Internet addiction. In the future, more program evaluation studies are also needed to evaluate the effectiveness of this kind of training program in Chinese and other societies.

\subsection{Research Limitations and Future Research Directions}

This study has three major limitations. First, this is a cross-sectional survey study; thus, the data might not establish a sound cause-effect relationship. Longitudinal studies should be conducted in the future. Second, a self-reported survey was adopted to measure the studied variables; thus, the data might have a socially desirable bias. Future studies with other sources or informants, such as peer, teacher, or parental reports, are needed to verify the results. Finally, this study only focused on the junior secondary students, who might have more time and chances to have an Internet addiction. Future studies should also include students in late primary school or early high school years to understand developmental trajectories of Internet addiction in adolescence.

\section{Conclusions}

This study explored the mediating roles of self-control and maladaptive cognitions in the path from mindfulness to Internet addiction. The dual-path mediation model was confirmed with a good model fit. First, this model indicated that mindfulness, self-control, maladaptive cognitions, and Internet addiction were significantly correlated. Second, the model exhibited that mindfulness had indirect negative effects on Internet addiction mediated by self-control. Third, the model also demonstrated that mindfulness indirectly negatively impacted Internet addiction mediated by the path of self-control to maladaptive cognitions. However, this dual-path mediation model did not differ between genders.

Author Contributions: J.W.: conceptualization, methodology, validation, formal analysis, investigation, data curation, and draft preparation; H.L.: conceptualization, writing, and editing. All authors have read and agreed to the published version of the manuscript.

Funding: This research received no external funding.

Institutional Review Board Statement: The study was conducted according to the guidelines of the Declaration of Helsinki, and approved by the Institutional Review Board of Hangzhou Normal University.

Informed Consent Statement: Informed consent was obtained from all subjects involved in the study.

Data Availability Statement: The data presented in this study are available on request from the corresponding author.

Acknowledgments: We are grateful to all the students and their parents in the participating school.

Conflicts of Interest: The authors declare no conflict of interest.

\section{References}

1. Levi, G.C.; Cohen, S.; Kaliche, S.; Sharaabi, K.; Cohen, D.; Tzur-Bitan, A. Weinstein. Sexual addiction, compulsivity, and impulsivity among a predominantly female sample of adults who use the internet for sex. J. Behav. Addict. 2020, 9, 83-92. [CrossRef] [PubMed]

2. Tian, Y.; Bian, Y.; Han, P.; Gao, F.; Wang, P. Associations between psychosocial factors and generalized pathological internet use in chinese university students: A longitudinal cross-lagged analysis. Comput. Hum. Behav. 2017, 72, 178-188. [CrossRef] 
3. Zeidi, I.S.; Divsalar, H.; Morshedi, H. The effectiveness of group cognitive-behavioral therapy on general self-efficacy, self-control, and internet addiction prevalence among medical university students. Soc. Health Behav. 2020, 3, 93-102. [CrossRef]

4. Amini, M.; Lotfi, M.; Fatemitabar, R.; Bahrampoori, L. The effectiveness of emotion-focused group therapy on the reduction of negative emotions and internet addiction symptoms. PCP 2020, 8, 1-8. [CrossRef]

5. Yu, L.; Zhou, X. Emotional competence as a mediator of the relationship between internet addiction and negative emotion in young adolescents in hong kong. Appl. Res. Qual. Life 2021, 3, 1-18. [CrossRef]

6. Gür, K.; Yurt, S.; Bulduk, S.; Atagöz, S. Internet addiction and physical and psychosocial behavior problems among rural secondary school students. Nurs. Health Sci. 2015, 17, 331-338. [CrossRef]

7. Trojak, B.; Zullino, D.; Achab, S. Brain stimulation to treat internet addiction: A commentary. Addict. Behav. 2017, 64, 363-364. [CrossRef]

8. Haan, J.L.; Masel, R. The influence of solution ph on rates of an electrocatalytic reaction: Formic acid electrooxidation on platinum and palladium. Electrochim. Acta 2009, 54, 4073-4078. [CrossRef]

9. Han, L.; Geng, J.; Jou, M.; Gao, F.; Yang, H. Relationship between shyness and mobile phone addiction in chinese young adults: Mediating roles of self-control and attachment anxiety. Comput. Hum. Behav. 2017, 76, 363-371. [CrossRef]

10. Khanna, S.; Greeson, J. A narrative review of yoga and mindfulness as complementary therapies for addiction. Complement. Ther. Med. 2013, 21, 244-252. [CrossRef]

11. Błachnio, A.; Przepiorka, A.; Benvenuti, M.; Mazzoni, E.; Seidman, G. Relations between facebook intrusion, internet addiction life satisfaction, and self-esteem: A study in italy and the usa. Int. J. Ment. Health Addict. 2019, 17, 793-805. [CrossRef]

12. Mamun, M.M.; Hossain, M.; Moonajilin, M.; Masud, J.; Griffiths, M. Does loneliness, self-esteem and psychological distress correlate with problematic internet use? A bangladeshi survey study. Asia-Pac. Psychiatry 2020, 12, e12386. [CrossRef]

13. Mo, P.K.H.; Chan, Y.; Wang, X.; Lau, J. Gender difference in the association between internet addiction, self-esteem and academic aspirations among adolescents: A structural equation modelling. Comput. Educ. 2020, 155, 103921. [CrossRef]

14. Agbaria, Q. Internet addiction and aggression: The mediating roles of self-control and positive affect. Int. J. Ment. Health Addict. 2020, 411, 1-13. [CrossRef]

15. Özdemir, Y.; Kuzucu, Y.; Ak, S. Depression, loneliness and internet addiction: How important is low self-control? Comput. Hum. Behav. 2014, 34, 284-290. [CrossRef]

16. Forrest, C.J.; King, D.; Delfabbro, P. Maladaptive cognitions predict changes in problematic gaming in highly-engaged adults: A 12-month longitudinal study. Addict. Behav. 2017, 65, 125-130. [CrossRef]

17. Gao, T.; Hu, Y.; Qin, Z.; Cao, R.; Liu, S.; Mei, S.; Meng, X. The role of school connectedness and maladaptive cognitions in the association between stress and internet addiction: A serial mediation model. Perspect. Psychiatr. Care 2019, 55, 728-733. [CrossRef] [PubMed]

18. Grapendorf, J.; Sassenberg, K.; Landkammer, F. Mindfulness is detrimental to performance in computer-mediated interdependent tasks. Comput. Hum. Behav. 2017, 74, 1-6. [CrossRef]

19. Brown, D.B.; Bravo, A.; Roos, C.; Pearson, M. Five facets of mindfulness and psychological health: Evaluating a psychological model of the mechanisms of mindfulness. Mindfulness 2015, 6, 1021-1032. [CrossRef]

20. Bajaj, B.; Gupta, R.; Pande, N. Self-esteem mediates the relationship between mindfulness and well-being. Personal. Individ. Differ. 2016, 94, 96-100. [CrossRef]

21. Bogusch, L.M.; Fekete, E.; Skinta, M. Anxiety and depressive symptoms as mediators of trait mindfulness and sleep quality in emerging adults. Mindfulness 2016, 7, 962-970. [CrossRef]

22. Liu, Q.; Zhang, D.; Yang, X.; Zhang, C.; Fan, C.; Zhou, Z. Perceived stress and mobile phone addiction in chinese adolescents: A moderated mediation model. Comput. Hum. Behav. 2018, 87, 247-253. [CrossRef]

23. Davis, R.A. A cognitive-behavioral model of pathological internet use. Comput. Hum. Behav. 2001, 17, 187-195. [CrossRef]

24. Shapiro, S.L.; Carlson, L.E.; Astin, J.; Freedman, B. Mechanisms of mindfulness. J. Clin. Psychol. 2006, 62, 373-386. [CrossRef] [PubMed]

25. Dong, X.; Xiang, Y.; Zhao, J.; Li, Q.; Zhang, W. How mindfulness affects benign and malicious envy from the perspective of the mindfulness reperceiving model. Scand. J. Psychol. 2020, 16, 436-442. [CrossRef] [PubMed]

26. Friese, M.; Messner, C.; Schaffner, Y. Mindfulness meditation counteracts self-control depletion. Conscious Cogn. 2012, 21, 1016-1022. [CrossRef]

27. Panek, E.T.; Bayer, J.B.; Dalcin, S.; Campbell, S.W. Automaticity, mindfulness, and self-control as predictors of dangerous texting behavior. Mob. Media Commun. 2015, 3, 383-400. [CrossRef]

28. Song, W.; Park, J. The influence of stress on internet addiction: Mediating effects of self-control and mindfulness. Int. J. Ment. Health Addict. 2019, 17, 1063-1075. [CrossRef]

29. Niculović, M.; Živković, D.; Manasijević, D.; Štrbac, N. Study of pathological internet use, behavior and attitudes among students population at technical faculty bor, university of belgrade. Comput. Hum. Behav. 2014, 39, 78-87. [CrossRef]

30. Sariyska, R.; Lachmann, B.; Markett, S.; Reuter, M.; Montag, C. Individual differences in implicit learning abilities and impulsive behavior in the context of internet addiction and internet gaming disorder under the consideration of gender. Addict. Behav. Rep. 2017, 5, 19-28. [CrossRef] [PubMed] 
31. Schimmenti, A.; Passanisi, A.; Caretti, V.; La-Marca, L.; Granieri, A.; Iacolino, C.; Gervasi, A.; Maganuco, N.; Billieux, J. Traumatic experiences, alexithymia, and internet addiction symptoms among late adolescents: A moderated mediation analysis. Addict. Behav. 2017, 64, 314-320. [CrossRef] [PubMed]

32. Jiang, Z.; Zhao, X. Brain behavioral systems, self-control and problematic mobile phone use: The moderating role of gender and history of use. Personal. Individ. Differ. 2017, 106, 111-116. [CrossRef]

33. Tian, Y.; Qin, N.; Cao, S.; Gao, F. Reciprocal associations between shyness, self-esteem, loneliness, depression and internet addiction in chinese adolescents. Addict. Res. Theory 2020, 114, 1-13. [CrossRef]

34. Huang, S.; Hu, Y.; Ni, Q.; Qin, Y.; Lü, W. Parent-children relationship and internet addiction of adolescents: The mediating role of self-concept. Curr. Psychol. 2019, 3, 1-15. [CrossRef]

35. Rębisz, S.; Sikora, I. Internet addiction in adolescents. Pract. Theory Syst. Educ. 2016, 11, 194-204. [CrossRef]

36. Deng, Y.Q.; Liu, X.H.; Rodriguez, M.A.; Xia, C.Y. The five facet mindfulness questionnaire: Psychometric properties of the chinese version. Mindfulness 2011, 2, 123-128. [CrossRef]

37. Tangney, J.P.; Baumeister, R.F.; Boone, A.L. High self-control predicts good adjustment, less pathology, better grades, and interpersonal success. J. Pers. 2004, 72, 271-324. [CrossRef]

38. Xiao, G.C.; Shi, J.J.; Ning, J.N. Study on the relationship between self-control and coping style of drug addicts in compulsory isolation. Chin. J. Drug Abus. Prev. Treat. 2018, 24, 88-90.

39. Davis, R.A.; Flett, G.L.; Besser, A. Validation of a new scale for measuring problematic internet use: Implications for preemployment screening. Cyberpsychol. Behav. 2002, 5, 331-345. [CrossRef]

40. Liang, X.Y. A Study on the Effect Mechanism of Online Social Support on Adolescents' Mental Health; Huazhong Normal University: Wuhan, China, 2008.

41. Gómez, P.; Harris, S.K.; Barreiro, C.; Isorna, M.; Rial, A. Profiles of internet use and parental involvement, and rates of online risks and problematic internet use among spanish adolescents. Comput. Hum. Behav. 2017, 75, 826-833. [CrossRef]

42. Ullman, J.B. Structural equation modeling: Reviewing the basics and moving forward. J. Pers. Assess. 2006, 87, 35-50. [CrossRef]

43. Hu, L.; Bentler, P.M. Cutoff criteria for fit indexes in covariance structure analysis: Conventional criteria versus new alternatives. Struct. Equ. Model. Multidiscip. J. 1999, 6, 1-55. [CrossRef]

44. Byrne, B.M. Structural Equation Modeling with Mplus: Basic Concepts, Applications, and Programming; Routledge: London, UK, 2012.

45. Gökçearslan, S..; Mumcu, F.K.; Haşlaman, T.; Çevik, Y.D. Modelling smartphone addiction: The role of smartphone usage, self-regulation, general self-efficacy and cyberloafing in university students. Comput. Hum. Behav. 2016, 63, 639-649. [CrossRef]

46. Köpetz, C.E.; Lejuez, C.W.; Wiers, R.W.; Kruglanski, A.W. Motivation and self-regulation in addiction: A call for convergence Perspect. Psychol. Sci. 2013, 8, 3-24. [CrossRef]

47. Kim, S.J. The Development and Verification of Mindfulness-Based Self-Regulation Program for Internet Craving. Ph.D. Thesis, Chungnam National University, Daejeon, Korea, 2012. Unpublished.

48. Arslan, G.; Cokun, M. Social exclusion, self-forgiveness, mindfulness, and internet addiction in college students: A moderated mediation approach. Int. J. Ment. Health Addict. 2021, 183, 1-15.

49. Garland, E.L.; Bryan, M.A.; Hanley, A.W.; Howard, M.O. Neurocognitive mechanisms of mindfulness-based interventions for addiction-sciencedirect. Cogn. Addict. 2020, 11, 283-293.

50. Schwebel, F.J.; Korecki, J.R.; Witkiewitz, K. Addictive behavior change and mindfulness-based interventions: Current research and future directions. Curr. Addict. Rep. 2020, 7, 117-124. [CrossRef] [PubMed]

51. Chi, X.L.; Liu, X.F.; Guo, T.Y.; Wu, M.X.; Chen, X.C. Internet addiction and depression in chinese adolescents: A moderated mediation model. Front. Psychiatry 2019, 10, 816. [CrossRef] [PubMed]

52. Kim, K.H. Mindfulness, self-regulation, and wisdom. Korean J. Clin. Psychol. 2008, 13, 285-306.

53. Guo, Y.; Sun, S.; Breitsmith, A.; Morrison, F.J.; Connor, M.D. Behavioral engagement and reading achievement in elementaryschool-age children: A longitudinal cross-lagged analysis. J. Educ. Psychol. 2014, 107, 332-347. [CrossRef]

54. Lepp, A.; Barkley, J.E.; Karpinski, A.C. The relationship between cell phone use, academic performance, anxiety, and satisfaction with life in college students. Comput. Hum. Behav. 2014, 31, 343-350. [CrossRef]

55. Piko, B.F.; Prievara, D.K.; Mellor, D. Aggressive and stressed? Youth's aggressive behaviors in light of their internet use, sensation seeking, stress and social feelings. Child. Youth Serv. Rev. 2017, 77, 55-61. [CrossRef] 